\title{
Surgical Management of Thoracic Disc Herniation: Anterior vs Posterior Approach
}

\author{
Ismail OLTULU ${ }^{1}$, Hemra $\mathrm{CIL}^{2}$, Sigurd BERVEN${ }^{3}$, Dean $\mathrm{CHOU}^{4}$, Aaron CLARK ${ }^{4}$, Mustafa Onur ULU ${ }^{5}$, \\ Christopher $\mathrm{AMES}^{4}$, Vedat DEVIREN ${ }^{3}$ \\ ${ }^{1}$ VM Medical Park Pendik Hospital, Department of Orthopeadics and Traumatology, Istanbul, Turkey \\ ${ }^{2}$ University of California, Department of Anesthesia and Reanimation, San Francisco, USA \\ ${ }^{3}$ University of California, Department of Orthopeadics and Traumatology, San Francisco, USA \\ ${ }^{4}$ University of California, Department of Neurosurgery, San Francisco, USA \\ ${ }^{5}$ Istanbul University-Cerrahpasa, Cerrahpasa Medical Faculty, Department of Neurosurgery, Istanbul, Turkey
}

Corresponding author: Ismail OLTULU ioltulu@hotmail.com

\section{ABSTRACT}

AIM: To compare outcomes and complications in patients with thoracic disc herniation (TDH) undergoing surgery with either the posterior or anterior approach.

MATERIAL and METHODS: A total of 86 patients, with 98 symptomatic TDHs, who underwent surgery in a single institution between 2007 and 2016, were included. Overall, 68 patients were in the anterior and 18 were in the posterior group. Ten patients underwent multilevel TDH surgery.

RESULTS: The groups were similar in age, sex, body mass index, and clinical symptoms. In the anterior group, 4 patients (5.9\%) had major complications, and 26 (38.2\%) had minor complications. In the posterior group, 6 patients (33.3\%) had major complications, and $4(22.2 \%)$ had minor complications. Visual analog scores at the final follow-up improved in both groups as compared to baseline preoperative scores $(p>0.05)$. The rate of neurological improvement in patients with myelopathy was significantly higher in the anterior group $(43 / 50)$ than in the posterior group $(8 / 14)(p<0.05)$.

CONCLUSION: The current study showed that higher rates of major complications in central and calcified paracentral TDHs are associated with posterior approaches when compared to anterior approaches. In addition, anterior approaches had superior neurological recovery and clinical outcomes. Therefore, we recommend the anterior approach for the treatment of calcified and/or non-calcified central and calcified paracentral TDH, while reserving posterior approaches for small non-calcified paracentral disc herniations.

KEYWORDS: Thoracic disc, Herniation, Posterior, Anterior, Calcification

\section{INTRODUCTION}

T The incidence of thoracic disc herniation (TDH) is estimated to occur in between $0.25 \%$ and $1 \%$ of all disc herniations $(10,32)$. The majority of TDHs are central or paracentral; however, far lateral disc herniations have also been reported. The female to male ratio for $\mathrm{TDH}$ is approximately $1: 1(3,32)$.The strongest indication for surgery is severe and/or progressive myelopathy. While surgery for pain control is controversial, patients achieve better symptomatic relief when the indication is radicular pain when compared to discogenic pain $(26,32)$. There is no consensus regarding the best surgical approach for treating symptomatic TDH. In the present study, surgical approaches for the treatment of TDH include posterolateral $(6,16,22,33)$, lateral $(14,36)$, anterior $(5)$,
Ismail OLTULU (D: : 0000-0001-9716-7795

Hemra CIL (D) : 0000-0001-7832-2542

Sigurd BERVEN (D) : 0000-0003-1006-5345
Dean CHOU (D) : 0000-0003-0310-8263

Aaron CLARK D : 0000-0002-6831-2663

Mustafa Onur ULU (D) : 0000-0002-6256-0869
Christopher AMES (10 : 0000-0003-2618-3098 Vedat DEVIREN (D : 0000-0002-7295-9814 
and video-assisted thoracoscopic surgery $(2,24)$. The main goal of surgery is to provide sufficient decompression and minimize manipulation of the compressed spinal cord (28). We aimed to compare outcomes and complications of anterior versus posterior approaches in a series of TDH patients undergoing surgery at the same institution.

\section{MATERIAL and METHODS}

The study protocol was approved by the Institutional Review Board. We retrospectively reviewed a prospectively maintained spine registry at the same academic institution to identify patients with TDHs who underwent surgical treatment between 2007 and 2016. The patients' clinical records were reviewed for demographic information, clinical presentation, radiographic studies, level of TDH, surgical approach, estimated blood loss (EBL), operation time, length of stay (LOS), perioperative complications, and clinical outcomes at the last follow-up. The patient population was separated into groups that underwent either an anterior or posterior approach and compared based on the previously mentioned parameters.

\section{Imaging Review}

Preoperative magnetic resonance imaging (MRI) was reviewed to document localization of the disc herniation, relation of the disc herniation to the spinal cord, and degree of spinal cord compression. In addition, all patients underwent computed tomography (CT) scans to assess the degree of calcification of the herniated disc. The level of disc herniation was marked preoperatively with a fiducial screw under CT guidance in some patients, and intraoperative localization with fluoroscopy was performed in others (35). Postoperative X-rays were taken in patients who underwent instrumented fusion, and MRI and CT scans were obtained in those with new or persistent symptoms.

\section{Outcome Analysis}

All patients were examined by an independent observer. Patients were assessed preoperatively and postoperatively at 6 weeks, 3 months, 6 months, 1 year, and yearly thereafter. Patients complete da visual analog scale (VAS), Oswestry Disability Index (ODI), and SF-36 health surveys as part of a prospectively maintained database. Neurological improvement was defined as resolved or improved bowel/bladder symptoms and/or improved lower extremity radiculopathy or weakness.

\section{Statistical Analysis}

Statistical analysis was conducted using the Number Cruncher Statistical System 2007 (Kaysville, UT, USA) software. Descriptive statistical methods (mean, standard deviation, median, frequency, ratio, minimum, and maximum) were usedin the data evaluation. Student $t$-test was performed for intergroup comparisons of quantitative data with normal distribution, and the Mann-Whitney $U$ test was used for intergroup comparisons of variables without normal distribution. Pearson chi-square test, Fisher exact test, and Yates's continuity correction test (Yates's corrected chi-square test) were used to compare qualitative data. Significance was evaluated at $p<0.01$ and $p<0.05$.

\section{RESULTS}

\section{Demographic and Perioperative Data}

A total of 86 patients with 98 disc herniation levels were treated in both groups. Eight patients had 2 levels of symptomatic disc herniations, and 2 patients had 3 levels. The T7-8 disc space was the most frequently involved level (18/86 patients; $20.9 \%$ )in the current cohort. The demographic data are summarized in Tables I, II, and III, and illustrative cases are presented in Figures 1A-F; 2A-F. Both groups were similar in age, sex, body mass index, and clinical symptoms (Table I). TDH characteristics in the anterior and posterior groups are summarized in Table II. In the anterior group, the mean canal occupancy rate was $43.45 \%$, while it was $48.8 \%$ in the posterior group $(p=0.445)$.

\section{Surgical Procedures}

In the anterior group ( $\mathrm{n}=68$ ), discectomy was performed in 56 patients using a minimally invasive lateral transthoracic trans/ retropleural approach (mini-LTTA), and 12 patients underwent thoracic discectomy via thoracotomy. All 86 cases underwent intraoperative neuromonitoring. In the posterior group $(n=18)$, discectomy was performed using a transfacet pediclesparing approach in 9 patients, a transpedicular approach in 4 patients, and a costotransversectomy in 1 patient. Four patients underwent laminectomy without discectomy.

No significant differences were found in length of surgery, EBL, or hospital LOS (Table III). Likewise, both groups had similar lengths of follow-up (Table III).

\section{Complications}

The complication profile of the present study is shown in Table IV. The posterior group had a significantly higher rate of major complications $(6 / 18 ; 33 \%)$ when compared to the anterior group $(4 / 68 ; 5.9 \%)(p=0.005)$. Conversely, minor complications were more common in the anterior group $(26 / 68 ; 38.2 \%$ vs. $4 / 18 ; 22.2 \%)(p=0.271)$.

In the anterior group, transient neurologic deterioration occurred in 1 patient with calcified central disc herniation. The patient's neurologic status regressed from preoperative American Spinal Injury Association (ASIA) E to postoperative ASIA D with full subsequent recovery at the last followup. Two patients in the posterior group had permanent neurological deterioration; both patients had calcified central disc herniation. Both patients were ASIA E preoperatively and ASIA A (1 patient) and B (1 patient) postoperatively. Transient neurological deterioration (ASIA C) occurred in 1 patient with non-calcified central disc herniation, with the patient regaining muscle strength close to preoperative levels after 1 year (ASAI E). Perioperative transient neurological deterioration occurred in 1 patient with calcified central disc herniation. One patient in the posterior group had an incomplete discectomy due to a marked decrease in intraoperative somato sensory-evoked potentials and motor-evoked potentials. While postoperative motor examination was close to normal, the patient's complaints regarding residual pressure persisted at the last follow-up. Overall, the posterior group had a significantly higher rate of neurological deterioration compared to the 
Table I: Demographic Data, Comorbidities, Perioperative Symptoms, Level of Herniated Disc of the Patients in Anterior and Posterior Groups

\begin{tabular}{|c|c|c|c|}
\hline & Anterior $(n=68)$ & Posterior $(n=18)$ & $\mathbf{p}$ \\
\hline Mean age in years (range) & $55.4(23-84)$ & $56.6(20-97)$ & 0.773 \\
\hline Male Gender (ratio) & $41(60.3 \%)$ & $12(66.7 \%)$ & 0.787 \\
\hline Mean body mass index in $\mathrm{kg} / \mathrm{m}^{2}$ (range) & $30.3(18.3-46.2)$ & $29.5(20.7-44.1)$ & 0.642 \\
\hline Comorbidites & n (\%) & n (\%) & \\
\hline Hypertension & 27 (39.7) & $9(50)$ & 0.434 \\
\hline Diabetes mellitus & $10(14.7)$ & $5(27.8)$ & 0.252 \\
\hline Obesity & $33(48.5)$ & $6(33.3)$ & 0.342 \\
\hline Cardiac disease & $12(17.6)$ & $5(27.8)$ & 0.531 \\
\hline Symptomps & $\mathrm{n}(\%)$ & $\mathrm{n}(\%)$ & \\
\hline Back pain & $55(80.9)$ & $5(27.8)$ & 0.000 \\
\hline Leg pain & $38(55.9)$ & $6(33.3)$ & 0.114 \\
\hline Ataxia & $26(38.2)$ & $7(38.9)$ & 1.000 \\
\hline Paraparesia & $25(36.8)$ & 4 (22.2) & 0.279 \\
\hline Urinary Incontinence & $16(23.5)$ & $5(27.8)$ & 0.761 \\
\hline Level of herniated disc & n (\%) & n (\%) & \\
\hline T2-3 & 0 & $2(11.1)$ & \\
\hline T5-6 & $4(5.9) \neq$ & $2(11.1)$ & \\
\hline T6-7 & $8(11.76) \neq$ ఈ & $1(5.6)$ 斗 & \\
\hline T7-8 & $15(22.05) h$ & $3(16.7)$ 电 $\odot$ & \\
\hline T8-9 & $8(11.76)$ 支 $\mathrm{f}+$ 米 $\square+$ & $2(11.1) \odot$ & \\
\hline T9-10 & $9(13.23)+\frac{1}{\square} \square+\delta$ & $4(22.2) \odot$ & \\
\hline $\mathrm{T} 10-11$ & $13(19.11)+$ t & $2(11.1)$ & \\
\hline $\mathrm{T} 11-12$ & $12(17.64)$ 末 & $3(16.7)$ & \\
\hline T12-L1 & $8(11.76) \neq$ & $2(11.1)$ & \\
\hline Total number of herniated disc levels & 77 & 21 & \\
\hline Signs & n (\%) & n (\%) & \\
\hline Myelopathy & $49(72.1)$ & $14(77.8)$ & 0.769 \\
\hline Radiculopathy & $52(76.05)$ & $8(44.4)$ & 0.019 \\
\hline Axial pain & $54(79.4)$ & $14(77.8)$ & 1.000 \\
\hline Bowel/bladder dysfunction & $21(30.9)$ & $6(33.3)$ & 1.000 \\
\hline Neurological improvement (myelopathy) & $42(61.8)$ & $\begin{array}{c}8 \text { (57.1 of patient with } \\
\text { myelopathy) }\end{array}$ & 0.282 \\
\hline
\end{tabular}

$\odot+2$ patient had 3 leveldisc herniation

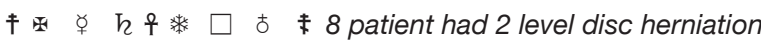

Table II: Characteristics of Thoracic Disc Herniation in Anterior and Posterior Groups ( $\mathrm{n}=$ number of discs)

\begin{tabular}{lcc}
\hline & Anterior $(\mathbf{n}=\mathbf{7 7})$ & Posterior $(\mathbf{n}=\mathbf{2 1})$ \\
\hline Central Disc & $39(50.65 \%)$ & $5(23.81 \%)$ \\
\hline Paracentral & $14(18.18 \%)$ & $6(28.57 \%)$ \\
\hline Central \& paracentral & $24(31.17 \%)$ & $10(47.62 \%)$ \\
\hline Disc calcification & $37(48.05 \%)$ & $8(38.10 \%)$ \\
\hline
\end{tabular}

anterior group $(\mathrm{p}<0.001)$. In addition, the risk of neurological deterioration in the posterior group was 19.1-fold higher than in the anterior group.

Two patients in the anterior group underwent secondary procedures. One patient had revision surgery due to pseudarthrosis 37 months after the initial TDH surgery. The other patient underwent posterior laminectomy and fusion 6 months after the initial surgery due to persistent narrowing at the same disc herniation level. Revision posterior fusion 
Table III: Operation Time, Blood Loss, Length of Stay, Follow-Up Periods in Anterior and Posterior Surgery Groups and Canal Occupancy Rate ( $n=$ number of patients)

\begin{tabular}{lccc}
\hline & Anterior Group $(\mathbf{n = 6 8 )}$ & Posterior Group $(\mathbf{n = 1 8 )}$ & $\mathbf{p}$ \\
\hline Operation Time (minutes) & $186.79(71-500)$ & $223.12(76-519)$ & 0.952 \\
\hline Blood loss $(\mathrm{mL})$ & $390.88(50-2000)$ & $602.78(25-2550)$ & 0.983 \\
\hline Length of stay (days) & $4.87(1-14)$ & $7.17(2-24)$ & 0.354 \\
\hline Follow up (months) & $17.07(1-61)$ & $22.06(2-70)$ & 0.352 \\
\hline Canal Occupancy & $43.45(16.4-83 \%)$ & $48.8(25.4-88 \%)$ & 0.445 \\
\hline
\end{tabular}

Numbers presented are means (with ranges).
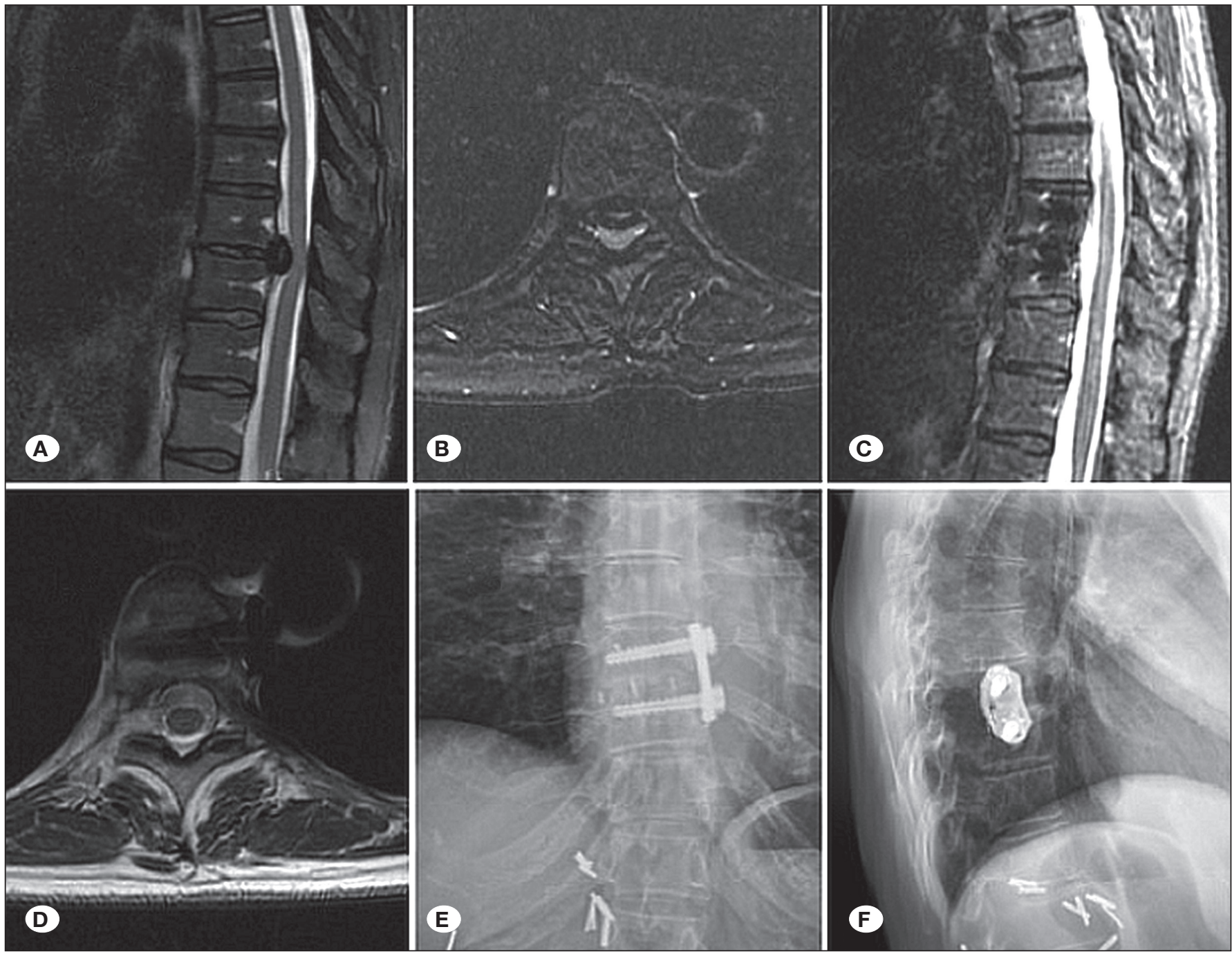

Figure 1: A 56-year-old female with back pain radiating to the left thigh and causing left leg numbness and weakness. A, B) Preoperative sagittal and axial MR images show T9-10 calcified central thoracic disc herniation with spinal cord compression. C, D) Postoperative sagittal and axial MR images. E, F) Anteroposterior and lateral radiographs reveal spinal cord decompression and lateral interbody fusion with anterolateral plating via the mini-open lateral transpleural approach. Estimated blood loss was $750 \mathrm{~mL}$, operation time was $156 \mathrm{~min}$, and length of stay was 3 days. 
was performed in 1 patient in the posterior group due to pseudarthrosis at 14 months.

In the anterior group, 6 (8.8\%) patients had dural tears; 4 of them had a calcified central disc herniation, 1 had a calcified paracentral disc herniation, and 1 had non-calcified central disc herniation. The patient with neurological deterioration had calcified central disc herniation and dural tear. Dural tears occurred in 4 (22\%) patients in the posterior group; 2 of them were associated with calcified central disc herniations, and 1 patient had permanent neurological deficits. One patient had non-calcified central disc herniation and transient neurological deterioration. The fourth patient with dural tear had a calcified paracentral disc herniation. All dural tears were repaired with primary suture and fibrin sealant (Tisseel, Baxter Healthcare Corp., Deerfield, IL, USA), and all tears healed without complication.
Overall, 26 minor complications (38.2\%) were noted in the anterior group. Two patients who required chest tube reinsertion developed a minimal pleural effusion. One patient with pneumonia was treated medically. Two patients developed ileus and 1 exhibited urinary retention, all of which resolved spontaneously. Four patients developed atelectasis, which resolved with treatment. A chest tube was not inserted in 1 patient who had a small amount of operative blood loss and developed a small pneumothorax, which healed spontaneously. Small apical pneumothoraces that healed spontaneously were observed in 2 patients. Pulmonary complications were observed in 7 patients $(12.3 \%)$ with singlelumen intubation and 3 (27.3\%) with double-lumen intubation and the difference was not statistically different $(p>0.05)$. Intercostal neuralgia lasting $>3$ months developed in $6(8.8 \%)$ patients in the anterior group; 4 had steroid injections, and
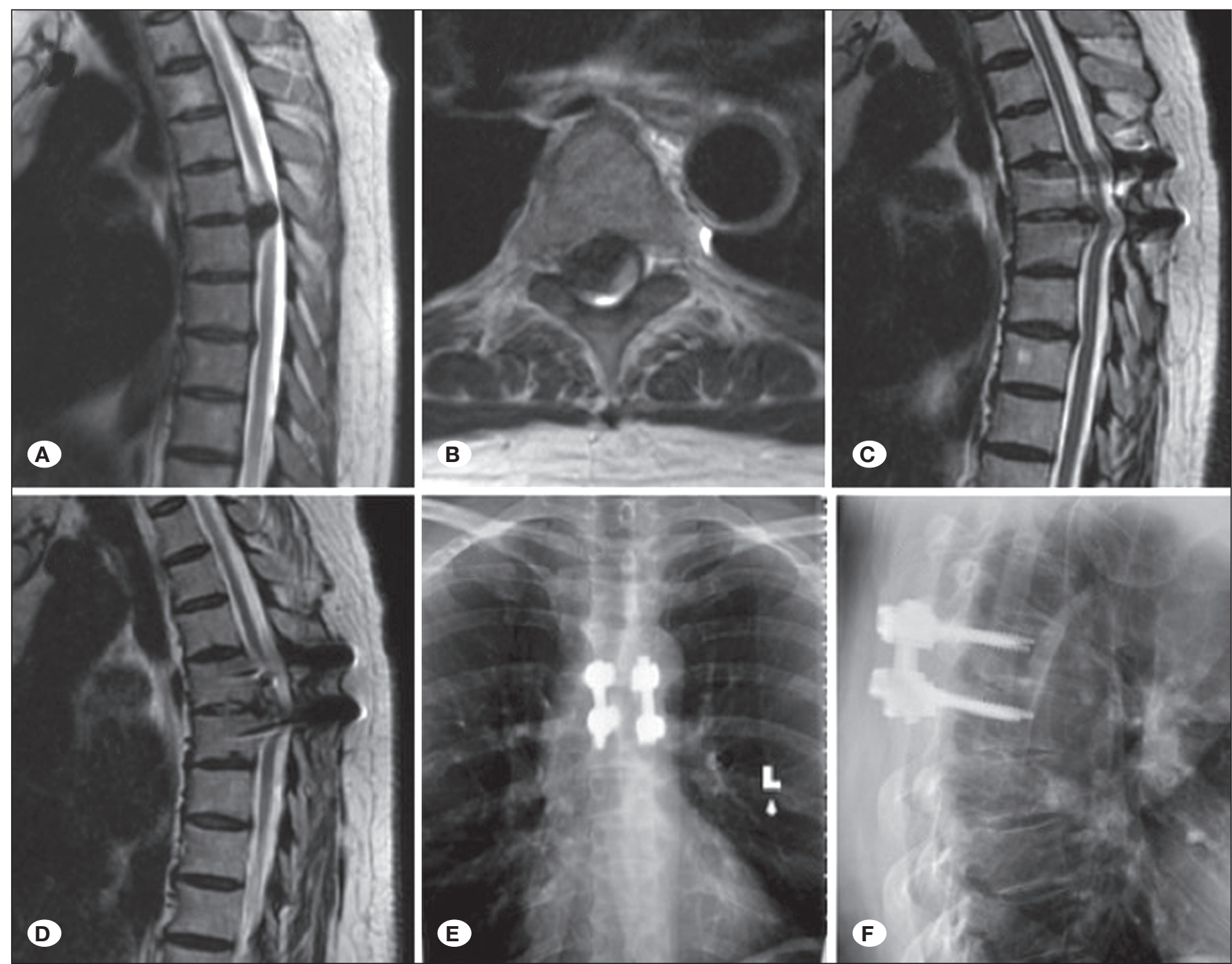

Figure 2: A 59-year-old male with ataxia and bilateral leg numbness and weakness. A, B) Preoperative sagittal and axial MR images show T5-6 calcified central thoracic disc herniation with spinal cord compression. C, D) Postoperative sagittal MR images show residual disc herniation. E, F) Anteroposterior and lateral radiographs show posterior plating via the posterior transfacet pedicle-sparing approach. Estimated blood loss was $150 \mathrm{~mL}$, operation time was $172 \mathrm{~min}$, and length of stay was 3 days. 
Table IV: Postoperative Complications in Anterior and Posterior Groups

\begin{tabular}{|c|c|c|c|c|}
\hline Complications & Anterior Group $(\mathrm{n}=68)$ & Posterior Group $(n=18)$ & $\mathbf{p}$ & ODDS $(95 \% \mathrm{Cl})$ \\
\hline Neurological Deterioration & $1(1.5 \%)$ & $4(22.2 \%)$ & 0.006 & 19.143 \\
\hline Pulmonary embolism & $1(1.5 \%)$ & 0 & 1.000 & \\
\hline Pseudarthrosis & $1(1.5 \%)$ & $1(5.6 \%)$ & 0.377 & 3.941 \\
\hline Repeated surgery & $1(1.5 \%)$ & $1(5.6 \%)$ & 0.377 & 3.941 \\
\hline Pulmonary complications" & $10(14.7 \%)^{\star}$ & 0 & 0.112 & \\
\hline Dural tear & $6(8.8 \%) \ddagger$ & $4(22.2 \%) \dagger キ$ & 0.207 & 2.952 \\
\hline lleus & $2(2.9 \%)$ & 0 & 1.000 & \\
\hline Urinary retention & $1(1.5 \%)$ & 0 & 1.000 & \\
\hline Intercostal neuralgia & $6(8.8 \%)$ & 0 & 0.336 & \\
\hline Rip fracture & $1(1.5 \%)$ & 0 & 1.000 & \\
\hline
\end{tabular}

"Pulmonary complications were pneumonia, pleural effusion, pnemothorax and atelectasis, *Two patient had atelectasis with small pnemothorax, ₹ 4 central calcified disc herniation, 1 paracentral calcified disc herniation, 1 non-calcified disc herniation, $\neq$ ₹ 2 central calcified disc herniation, 1 non-calcified disc herniation, 1 paracentral non-calcified disc.

Table V: Clinical Outcomes of the Patients

\begin{tabular}{lcc}
\hline & Anterior Group (n=68) & Posterior Group (n=18) \\
\hline Postoperative neurological improvement & $42 / 49$ patients $(85.7 \%)^{*}$ & $8 / 14$ patients $(57.1 \%)$ \\
\hline VAS score-preoperative $^{*}$ & 7.6 & 6.6 \\
\hline VAS score-last control $^{*}$ & $4.5^{\#}$ & 5.72 \\
\hline ODI score-preoperative & 50.75 & 49.67 \\
\hline ODI score-last control & $38.55^{\#}$ & 48.44 \\
\hline PCS score-preoperative* & 28.91 & 35.09 \\
\hline PCS score-last control $^{*}$ & $35.87^{\#}$ & 33.97 \\
\hline MCS scores-preoperative & 37.34 & 40.80 \\
\hline MCS scores-last control $^{*}$ & $53.78^{\#}$ & 41.59
\end{tabular}

${ }^{*} p<0.05$ compared to posterior group, $" p<0.05$ compared to respective preoperative score.

2 were managed medically. A fractured rib due to retraction occurred in 1 patient and recovery was uneventful.

Neurological status and pain scores were evaluated at the last follow-up (Table V). The anterior group had higher rates of postoperative neurological improvement compared to the posterior group (85.7 vs. $57.1 \%$, respectively; $p<0.05$ ). The posterior group had significantly improved postoperative VAS, ODI, SF-36 physical component summary (PCS), and mental component summary (MCS) scores over their preoperative scores $(p<0.05)$ while the anterior group remained stable $(p>0.05)$.

\section{DISCUSSION}

Surgical management for TDH is technically demanding and associated with a considerable complication profile. Surgical approaches vary depending on the surgeon's experience, disc level, disc location in the spinal canal, and patient comorbidities, and the ideal surgical approach remains controversial $(4,7,8,11,15,21,30,33)$.

The present study revealed a higher rate of major complications in central and calcified paracentral disc herniations as a result of posterior approaches when compared to anterior approaches. Moreover, anterior approaches were associated with superior neurological recovery and clinical outcomes. Roelz et al. reported a 10-year experience treating giant TDH with mini-TTA, and they found no significant improvement in the modified Japanese Orthopaedic Association (mJOA) score in the immediate postoperative period, and they detected a non-significant improvement at the last control values. 
Sensory deficits improved significantly in all patients and the recovery was faster than motor deficits (30).

Wait et al. reported on 121 patients who underwent thoracoscopic surgery, 68 of whom presented with myelopathy. Frankel grade improved in 50 patients $(73.5 \%)$ and was maintained in $18(26.5 \%)(37)$.

Anand et al. defined clinical success as a $20 \%$ improvement in the Oswestry score at the final follow-up and reported clinical success in $73 \%$ of patients who underwent video-assisted thoracoscopic discectomy (2). Based on the same criteria, clinical success in the current study was $45.7 \%$ in patients in the anterior group and $33.3 \%$ in the posterior group. When thoracotomy cases were excluded from the anterior group, clinical success ratio was set to $54.4 \%$.

While the posterior group had a higher rate of major complications (5.9\% vs. $33.3 \%$; $p=0.005)$, the anterior group had moreminor complications (38.2\% vs. $22.7 \%$; $p=0.271$ ). Postoperative atelectasis, pneumothorax, pneumonia, significant blood loss, and severe post-thoracotomy pain were significantly higher for the standard anterior approach $(5,12,15,20,21)$.

Whereas single-lumen endotracheal tube was applied in the surgeries using mini-LTTA, the double-lumen endotracheal tube was used in the thoracotomy surgeries. No statistically significant difference was seen between the groups regarding pulmonary complications. Chest tubes were routinely placed in both groups except in 1 patient. Arts et al. reported 18\% of pulmonary complications such as pneumonia and pleural effusion and abandoned the routine use of chest tubes (4).

Strom and colleagues reported a $2 \%$ rate of pulmonary complications using the anterior approach, which they attributed to the routine use of chest tubes despite using minimally invasive methods; hence, they recommend routine chest tube insertion for reducing pulmonary complications (34).

However, complication rates in the current study were lower due to minimally invasive methods and thoracoscopic methods, and pulmonary complication rates were consistent with previous studies $(2,4,14,27,32,34,37)$.

Intercostal neuralgia is typically seen after the anterior approach, spontaneously resolving within a few months. Intercostal blockade or radiofrequency rhizotomy is effective in cases where the pain is unresponsive to medical therapy $(2,18)$. In the current study, intercostal neuralgia lasting $>3$ months developed in 6 (8.8\%) patients in the anterior group, 4 of whom improved without sequelae with intercostal blocks, and 2 received medical therapy. Khoo et al. reported 9 patients who experienced numbness for a year and 4 patients with persistent intercostal neuralgia (22).

Durotomy was observed in 6 patients in the anterior group and 4 in the posterior group, all of which were repaired successfully. Eight of 10 patients with a dural tear had central disc herniation, 7 of which were calcified. Arts and Bartels stated that cerebrospinal fluid leakage was one of the most frequently observed complications at a rate of $18 \%$ in patients with TDH treated with mini-open TTA approaches, and they attributed the rate of leakage to dural adherence to the disc due to calcification (4).

Our present series suggests a lower rate of durotomy (8.8\%) using the anterior approach, with a much higher rate $(22 \%)$ using the posterior approach. Despite having different pathoanatomy due to different indications (smaller/non-calcified disc herniation) for posterior approaches, a risk remains for a dural laceration and neurological injury due to manipulation of the thecal sac $(13,25)$.

In addition, anterior approach-associated neurologic complications have been reported in the literature (Table VI). Moran et al. reported transient neurological deterioration in 2 of 17 patients with giant TDH treated using mini-TTA (27). Strom et al. reported permanent neurological deterioration in 1 patient in their series including 64 patients treated thoracoscopically (34).

Kapoor et al. reported 2 cases of postoperative late-onset neurological complications due to herniation of the spinal cord as a result of anterior bone decompression after anterior approach (19). They also reported a patient with thoracic disc herniation who had postoperative late-onset neurological complications due to residual disc as a result of costotrans versectomy. In another patient, a residual disc was detected by $\mathrm{MRI}$ and treated using a posterior transthoracic approach (19).

Roelz et al. reported 2 cases with severe postoperative paraparesis immediately after mini-TTA (30). Both patients had good preoperative neurological status (mJOA 10 and 11, respectively) and both had large densely calcified herniated discs with intradural extension. Of these two patients one regained the pre-operative neurological status (mJOA 11) after 6 months. The other patient regained ambulation after 6 months following the operation and recovered to a mJOA of $8 / 13(30)$.

In the present study, 1 patient with calcified central disc herniation in the anterior group developed transient neurological deterioration, and muscle strength was fully recovered at 12-month follow-up. This outcome was consistent with previously reported neurologic complication rates of thoracic disc surgery using the anterior approach $(4,5,27,29,34)$. In the posterior group, permanent neurological deterioration occurred in 2 patients and transient neurologic deterioration in 2 patients. All 4 patients had central disc herniations (3 calcified). We think the high rate of a neurologic deficit with the posterior approach is related to the type of herniated disc. While the rate of central disc herniations was similar in the anterior (52 patients, $76.5 \%$ ) and posterior (14 patients, $77.8 \%$ ) groups, the posterior group had a higher rate of neurological deficit, which is probably due to the extensive dural (hence, spinal cord) manipulation to reach in and remove the ventral disc herniation. Moreover, disc herniation often indents the spinal cord to the point that a posterior approach to reach the herniation will actually require dorsal retraction of the cord because the lateral aspect of the cord is, in fact, ventral to the herniated disc, which may be one reason for the higher rate of neurological injury with this approach. 
Oltulu I. et al: Thoracic Disc Herniations

Table VI: Literature Review of Complication and Neurological Deterioration Rates in Thoracic Disc Herniation Patients During Anterior vs Posterior Surgical Approach ( $\mathrm{n}=$ number of patients)

\begin{tabular}{|c|c|c|c|c|c|c|c|}
\hline & & Year & $\mathbf{N}$ & Approach & $\begin{array}{c}\text { Complications } \\
\mathrm{n}(\%)\end{array}$ & $\begin{array}{c}\text { Neuro deterioration } \\
\mathrm{n}(\%)\end{array}$ & $\begin{array}{r}\text { Class of } \\
\text { evidence }\end{array}$ \\
\hline \multirow{8}{*}{$\begin{array}{l}\frac{\tilde{r}}{0} \\
\frac{\tilde{\alpha}}{w} \\
\frac{\mathbf{L}}{\mathbf{z}}\end{array}$} & Anand $^{2}$ & 2002 & 100 & VATS & $24(24)$ & $0(0)$ & IV \\
\hline & Wait ${ }^{37}$ & 2012 & 121 & Thoracoscopic & $20(16,7)$ & $0(0)$ & IV \\
\hline & Moran 279 & 2012 & 17 & Mini LTTA & $10(75)$ & $2(11,8)$ ** & IV \\
\hline & Uribe ${ }^{39}$ & 2012 & 60 & Mini LTTA & $16(26,6)$ & $1(1,7)^{\dagger}$ & IV \\
\hline & Kasliwal $^{20}$ & 2011 & 17 & Mini TTA & 0 & 0 & IV \\
\hline & Arts $^{4}$ & 2014 & 56 & Mini TTA & $21(38)$ & $3(5,4)^{\dagger+}$ & III \\
\hline & Bransford $^{7}$ & 2010 & 10 & Anterior open TT & $3(30)$ & 0 & III \\
\hline & Current Study & 2017 & 68 & Mini LTTA \& Open TT & $30(44)$ & $1(1,5)^{\star \star}$ & III \\
\hline \multirow{4}{*}{ 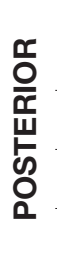 } & Bransford $^{6}$ & 2010 & 18 & $\begin{array}{l}\text { Transfacet pedicle- } \\
\text { sparing }\end{array}$ & $6(33)$ & $1(5,5)$ & III \\
\hline & Arts $^{4}$ & 2014 & 44 & Transpedicular & $2(5)$ & $1(2)$ * & III \\
\hline & Foreman ${ }^{16}$ & 2016 & 23 & Lateral extracavitary & NA & $1(4,3)^{*}$ & IV \\
\hline & Curent study & 2017 & 18 & Posterior & $10(55)$ & $4(22) * \star *$ & III \\
\hline
\end{tabular}

Q Giant thoracic disc herniation, * Permanant Neurological Deterioration, ** Transient Neurological Deterioration, *** 2 patient had Permanant neurological Deterioration 2 had transient neurological deterioration, $\boldsymbol{t}+$ worsened one or more grades on the ASIA scale, $\boldsymbol{t}$ new lower-extremity weakness.

Sivakumaran et al. reported huge calcified TDH after right-sided transfacet/transpedicular surgery. Ten days after surgery, they reoperated the patient due to residual disc herniation using a left-sided pedicle-sparing approach. However, they detected residual disc herniation after the second operation; thus, they performed a third operation with screw-rod instrumented stabilization for bilateral facet destabilization (31).

Our study showed that calcified central disc herniation surgically addressed using a posterior approach increases the risk of neurologic deficit 19.1-fold when compared with the anterior approach.

A literature review of the complications and neurological deterioration rates in TDH patients undergoing the anterior versus posterior surgical approach is listed in Table VI.

In the present study, none of the patients who underwent laminectomy had neurologic deterioration, and they had neurologic improvement at the short-term follow-up. Prior to the description of modern surgical techniques, the treatment of TDHs included laminectomy and discectomy, which resulted in catastrophic complications (23). Currently, this technique is rarely used due to poor clinical outcomes $(17,23)$. Laminectomy without discectomy, on the other hand, can be applied in certain patients, especially for those who require acute decompression (9). In the present study, none of the patients who underwent laminectomy had neurologic deterioration, and they had neurologic improvement at the short-term follow-up. To our knowledge, no study has reported long-term outcomes of laminectomy only without disc removal for TDH.
Alonso and Kasliwal reported a 55-year-old patient who underwent posterior stabilization with laminectomy without discectomy. After surgery, the patient's neurological condition improved and remained stable (1). Brauge et al. performed laminectomy in $10 \mathrm{TDH}$ patients with acute myelopathy, first, to stabilize the patients' neurological condition. Next, during a second surgical period, they performed thoracoscopic discectomy in 6 patients. Nine patients had neurological recovery, and neurological condition stabilized in 1 patient after laminectomy (8). We agree with the current literature that neurological deterioration rate increases when laminectomy is performed with discectomy and we think laminectomy without discectomy stabilizes neurological status for a short period.

Our study has several limitations. First, it is a retrospective study; however, it was difficult to perform a prospective randomized trial due to the low incidence of TDH and a wide variety of surgical procedures. Another limitation is the selection bias that occurred when choosing the anterior versus posterior approach, which may be a factor when considering the neurological outcomes. Put another way, an anterior approach may have been chosen in patients with disc herniation so severe that a posterior approach would not have been feasible or safe, and a posterior approach may have been chosen in patients with less severe disc herniation. Moreover, an inherent selection bias exists based on surgeon experience, availability of a thoracic surgeon for surgeons who do not or cannot perform the thoracotomy alone, or medical comorbidities precluding an anterior approach. Long-term follow-up is not available for all patients, which may affect the final revision rates due to 
pseudarthrosis. However, short-term follow-up is satisfactory for monitoring neurological improvement. Patients who developed perioperative neurological deficits were followed up for 29.2 months.

\section{CONCLUSION}

We found a lower rate of neurological injury for calcified central $\mathrm{TDH}$ with the anterior compared with the posterior approach. Although pulmonary complications are more common with anterior approaches, they resolve quickly with treatment and are a lesser source of morbidity when compared to profound neurologic deficits. Therefore, one should consider treating calcified central disc herniations via the anterior approach and performing posterior approaches for small, non-calcified paracentral disc herniations.

\section{- REFERENCES}

1. Alonso F, Kasliwal MK: Regression of giant calcified thoracic disk and spinal cord compression following thoracic laminectomy and posterior instrumented fusion. World Neurosurg 110:64, 2018

2. Anand N, Regan JJ: Video-assisted thoracoscopic surgery for thoracic disc disease: Classification and outcome study of 100 consecutive cases with a 2-year minimum follow-up period. Spine 27:871-879, 2002

3. Arce CA, Dohrmann GJ: Herniated thoracic disks. Neurol Clin 3:383-392, 1985

4. Arts MP, Bartels RH: Anterior or posterior approach of thoracic disc herniation? A comparative cohort of mini-transthoracic versus transpedicular discectomies. Spine J 14:1654-1662, 2014

5. Ayhan S, Nelson C, Gok B, Petteys RJ, Wolinsky JP, Witham TF, Bydon A, Gokaslan ZL, Sciubba DM: Transthoracic surgical treatment for centrally located thoracic disc herniations presenting with myelopathy: A 5-year institutional experience. J Spinal Disord Tech 23:79-88, 2010

6. Bransford R, Zhang F, Bellabarba C, Konodi M, Chapman JR: Early experience treating thoracic disc herniations using a modified transfacet pedicle-sparing decompression and fusion. J Neurosurg Spine 12:221-231, 2010

7. Bransford RJ, Zhang F, Bellabarba C, Lee MJ: Treating thoracic-disc herniations: Do we always have to go anteriorly? Evid Based Spine Care J 1:21-28, 2010

8. Brauge D, Horodyckid C, Arrighi M, Reina V, Eap C, Mireau E, Bertrand B, Aldéa S, Gaillard S: Management of giant thoracic disc herniation by thoracoscopic approach: Experience of 53 cases. Oper Neurosurg 2018 (Epub ahead of print)

9. Brauge D, Madkouri R, Reina V, Bennis S, Baussart B, Mireau E, Aldea S, Gaillard S: Is there a place for the posterior approach in cases of acute myelopathy on thoracic disc hernia? World Neurosurg 107:744-749, 2017

10. Brown CW, Deffer PA, Akmakjian J, Donaldson DH, Brugman $\mathrm{JL}$ : The natural history of thoracic disc herniation. Spine 17:S97-102, 1992
11. Carr DA, Volkov AA, Rhoiney DL, Setty P, Barrett RJ, Claybrooks R, Bono PL, Tong D, Soo TM: Management of thoracic disc herniations via posterior unilateral modified transfacet pedicle-sparing decompression with segmental instrumentation and interbody fusion. Global Spine J 7:506513,2017

12. Court C, Mansour E, Bouthors C: Thoracic disc herniation: Surgical treatment. Orthop Traumatol Surg Res 104:S31-S40, 2018

13. Debnath UK, McConnell JR, Sengupta DK, Mehdian SM, Webb JK: Results of hemivertebrectomy and fusion for symptomatic thoracic disc herniation. Eur Spine J 12:292299, 2003

14. Deviren V, Kuelling FA, Poulter G, Pekmezci M: Minimal invasive anterolateral transthoracic transpleural approach: A novel technique for thoracic disc herniation. A review of the literature, description of a new surgical technique and experience with first 12 consecutive patients. J Spinal Disord Tech 24:E40-48, 2011

15. Fessler RG, Sturgill M: Review: Complications of surgery for thoracic disc disease. Surg Neurol 49:609-618, 1998

16. Foreman PM, Naftel RP, Moore TA 2nd, Hadley MN: The lateral extracavitary approach to the thoracolumbar spine: $A$ case series and systematic review. J Neurosurg Spine 24:570579, 2016

17. Hulme A: The surgical approach to thoracic intervertebral disc protrusions. J Neurol Neurosurg Psychiatry 23:133-137, 1960

18. Johnson JP, Filler AG, Mc Bride DQ: Endoscopic thoracic discectomy. Neurosurg Focus 9:e11, 2000

19. Kapoor S, Amarouche M, Al-Obeidi F, JM UK-I, Thomas N, Bell D: Giant thoracic discs: Treatment, outcome, and followup of 33 patients in a single centre. Eur Spine J 27:1555-1566, 2018

20. Kasliwal MK, Deutsch H: Minimally invasive retropleural approach for central thoracic disc herniation. Minim Invasive Neurosurg 54:167-171, 2011

21. Kerezoudis P, Rajjoub KR, Goncalves S, Alvi MA, Elminawy M, Alamoudi A, Nassr A, Habermann EB, Bydon M: Anterior versus posterior approaches for thoracic disc herniation: Association with postoperative complications. Clin Neurol Neurosurg 167:17-23, 2018

22. Khoo LT, Smith ZA, Asgarzadie F, Barlas Y, Armin SS, Tashjian $\mathrm{V}$, Zarate B: Minimally invasive extracavitary approach for thoracic discectomy and interbody fusion: 1-year clinical and radiographic outcomes in 13 patients compared with a cohort of traditional anterior transthoracic approaches. J Neurosurg Spine 14:250-260, 2011

23. Logue V: Thoracic intervertebral disc prolapse with spinal cord compression. J Neurol Neurosurg Psychiatry 15:227241, 1952

24. McAfee PC, Regan JR, Fedder IL, Mack MJ, Geis WP: Anterior thoracic corpectomy for spinal cord decompression performed endoscopically. Surg Laparosc Endosc 5:339-348, 1995

25. McCormick WE, Will SF, Benzel EC: Surgery for thoracic disc disease. Complication avoidance: Overview and management. Neurosurg Focus 9:e13, 2000 
26. Mclnerney J, Ball PA: The pathophysiology of thoracic disc disease. Neurosurg Focus 9:e1, 2000

27. Moran C, Ali Z, Mc Evoy L, Bolger C: Mini-open retropleural transthoracic approach for the treatment of giant thoracic disc herniation. Spine 37:E1079-1084, 2012

28. Oppenlander ME, Clark JC, Kalyvas J, Dickman CA: Surgical management and clinical outcomes of multiple-level symptomatic herniated thoracic discs. J Neurosurg Spine 19:774-783, 2013

29. Quint U, Bordon G, Preissl I, Sanner C, Rosenthal D: Thoracoscopic treatment for single level symptomatic thoracic disc herniation: A prospective followed cohort study in a group of 167 consecutive cases. Eur Spine J 21:637-645, 2012

30. Roelz R, Scholz C, Klingler JH, Scheiwe C, Sircar R, Hubbe U: Giant central thoracic disc herniations: Surgical outcome in 17 consecutive patients treated by mini-thoracotomy. Eur Spine J 25:1443-1451, 2016

31. Sivakumaran R, Uschold TD, Brown MT, Patel NR: Transfacet and transpedicular posterior approaches to thoracic disc herniations: Consecutive case series of 24 patients. World Neurosurg 120: e921-e931, 2018

32. Stillerman CB, Chen TC, Couldwell WT, Zhang W, Weiss MH: Experience in the surgical management of 82 symptomatic herniated thoracic discs and review of the literature. J Neurosurg 88:623-633, 1998
33. Stillerman CB, Chen TC, Day JD, Couldwell WT, Weiss MH: The transfacet pedicle-sparing approach for thoracic disc removal: Cadaveric morphometric analysis and preliminary clinical experience. J Neurosurg 83:971-976, 1995

34. Strom RG, Mathur V, Givans H, Kondziolka DS, Perin NI: Technical modifications and decision-making to reduce morbidity in thoracic disc surgery: An institutional experience and treatment algorithm. Clin Neurol Neurosurg 133:75-82, 2015

35. Upadhyaya CD, Wu JC, Chin CT, Balamurali G, Mummaneni PV: Avoidance of wrong-level thoracic spine surgery: Intraoperative localization with preoperative percutaneous fiducial screw placement. J Neurosurg Spine 16:280-284, 2012

36. Uribe JS, Smith WD, Pimenta L, Hartl R, Dakwar E, Modhia UM, Pollock GA, Nagineni V, Smith R, Christian G, Oliveira L, Marchi L, Deviren V: Minimally invasive lateral approach for symptomatic thoracic disc herniation: Initial multicenter clinical experience. J Neurosurg Spine 16:264-279, 2012

37. Wait SD, Fox DJ Jr, Kenny KJ, Dickman CA: Thoracoscopic resection of symptomatic herniated thoracic discs: Clinical results in 121 patients. Spine 37:35-40, 2012 